In loco intellegentia: human factors for the future European train driver

Mark S. Young, Neville A. Stanton and Guy H. Walker

Corresponding address:

School of Engineering and Design

Brunel University

Uxbridge

Middlesex, UB8 3PH

UK

Tel: +44 (0)1895266527

Fax: +44 (0)1895269763

Email: m.young@brunel.ac.uk 


\title{
In loco intellegentia: human factors for the future European train driver
}

\begin{abstract}
The European Rail Traffic Management System (ERTMS) represents a step change in technology for rail operations in Europe. It comprises track-to-train communications and intelligent on-board systems providing an unprecedented degree of support to the train driver. ERTMS is designed to improve safety, capacity and performance, as well as facilitating interoperability across the European rail network. In many ways, particularly from the human factors perspective, ERTMS has parallels with automation concepts in the aviation and automotive industries. Lessons learned from both these industries are that such technology raises a number of human factors issues associated with train driving and operations. The interaction amongst intelligent agents throughout the system must be effectively coordinated to ensure that the strategic benefits of ERTMS are realised. The present paper discusses the psychology behind some of these key issues, such as mental workload, interface design, user information requirements, transitions and migration, and communications. Relevant experience in aviation and vehicle automation is drawn upon to give an overview of the human factors challenges facing the UK rail industry in implementing ERTMS technology. By anticipating and defining these challenges before the technology is implemented, it is hoped that a proactive and structured programme of research can be planned to meet them.
\end{abstract}

KEYWORDS: train driving, automation, mental workload, interface design, communications 


\section{INTRODUCTION}

The first few decades of the $21^{\text {st }}$ century are set to see a technological revolution in European rail travel (RSSB, 2005). With the Channel Tunnel in place between England and France, and frequent international traffic across continental Europe, there has emerged a need to harmonise operations between the member countries (RSSB, 2005). At the heart of this principle sits a brand new technology - the European Rail Traffic Management System (ERTMS).

ERTMS will provide a unified approach to train control, signalling and communications, in order to achieve greater mobility for trains across the European rail network. In addition to interoperability, the system will provide improved safety with automatic train protection, and increased capacity by better management of traffic. Needless to say, though, such a radical change in operations will have a significant impact on the human elements of the system, and there is currently considerable effort to address the human factors issues of ERTMS at an early stage in its development.

Today's train drivers perform fundamentally the same set of tasks as those of the first steam locomotives. Although the traction technology has changed, and specific rules and procedures have evolved over time, the traditional driving task consists of monitoring lineside signals and controlling the speed of the train in accordance with the movement authority that those signals provide. The signalling system is designed to maintain separation between trains by keeping at least one 'block' (i.e., section of track between two signals) free from one train to the next. Signallers, typically in centralised control rooms these days, monitor increasingly automated route settings and adjust signals and points to facilitate the safe and expeditious movement of traffic. The whole 
system can be represented by a network of mostly human team members working together to achieve an objective (cf. Walker et al., this issue).

ERTMS is a step change in that system, adding a level of technological intelligence never before seen on the railways. Currently, the most visible aspect of the system is in the driver's cab, as the driver-machine interface (DMI) presents movement authority and other routing information which has traditionally been displayed on the lineside (see CENELEC, 2000). Such an enhanced level of information means that ultimately we will no longer need lineside signals, and they will be removed. This single innovation alone will have purported benefits of improved driver situation awareness, increased efficiency in train control (i.e., optimising the timetable while maintaining safe stopping distances), and increased trackside safety (via a reduced need for trackside maintenance activities).

However, human factors experience in other domains suggests that there may be shortfalls in these expected benefits (e.g., Stanton and Marsden, 1996). The DMI consists of a single VDU touchscreen, although key data (such as speed) are also presented on redundant analogue dials. As such, the introduction of ERTMS will have a similar impact on the train driver as the glass cockpit concept has had on aircraft pilots, or as in-vehicle information systems (such as navigation displays) have had on car drivers. What the driver needs to know, and how that information is presented, are crucial questions in avoiding the possibility of driver distraction. Furthermore, the increased use of automatic protection systems is beginning to mirror the level of automation in aircraft and, more recently, in cars (see Walker, Stanton and Young, 2001 , for a discussion on the technology trajectory of vehicle automation). Indeed, the concept of automated separation is akin to Automatic Intelligent Cruise Control in cars, 
which can compensate for (lack of) human expertise - but it can also have its own problems, such as how to maintain driver attention and awareness of what the system is doing (e.g., Stanton and Young, this issue; Young and Stanton, 2004). Consequently, whilst the actual applications may appear relatively diverse, many of the underlying human factors issues addressed in these other transport domains will be applicable to future European rail operations.

Thus we see the potential problems facing the train driver, particularly in the UK (as we shall see later), include mental workload, situation awareness, interface design, transitions and migration to ERTMS, dependence on lineside information, as well as communications with other agents in the system (i.e., signallers). Previous work has drawn many of these concepts together to propose a psychological model of car driving with automation (Stanton and Young, 2000a); the present paper lays some of the groundwork for a similar effort in train driving. We discuss the main human factors concerns and summarise the psychological research behind them. Relevant research from the aviation and automotive domains is drawn upon in an effort to transfer lessons learned to the rail industry. Many of the issues have already been discussed elsewhere, but not specifically applied to railway operations. Common problems, which transcend the boundaries of the actual transport domain, are prevalent in human factors, and these are brought out in the present paper. Ultimately, this paper describes the foundation for a proactive series of studies (which is already underway in the UK rail industry) intended to address these problems before the technology is implemented - an idealistic opportunity which rarely exists in human factors. Firstly, though, some background to ERTMS technology itself is provided. 


\section{WHAT IS ERTMS?}

There are three main components to the ERTMS technology: the European Train Control System (ETCS), the European Traffic Management Layer (ETML), and the Global System for Mobile communications - Railway (GSM-R).

The ETCS element is the primary control system onboard the train. Its most visible aspect is the DMI, which displays a wealth of information about train movement, including speed (and speed restrictions), movement authority, and route planning information (such as gradients, neutral sections, tunnels etc.). Behind this interface, though, the system incorporates automatic train protection (ATP), which calculates braking curves and intervenes with a brake application if the driver is on course to exceed a speed limit or movement authority. In theory, when ETCS is fully enabled, it should be impossible to pass a signal at danger. Various indications on the DMI continuously inform the driver about these limits, such that s/he can control the train appropriately. Figure 1 is a sample screenshot showing these indications; in particular note the speed limit and movement authority bar around the speedometer, as well as the planning display on the right, giving route information on an exponential scale up to four kilometers in advance. Further information on the DMI can be found in the European Standard document (CENELEC, 2000). 
Young, M. S., Stanton, N. A. \& Walker, G. H. (2006). In loco intellegentia: human factors for the future European train driver. International Journal of Industrial and Systems Engineering, 1(4), 485-501

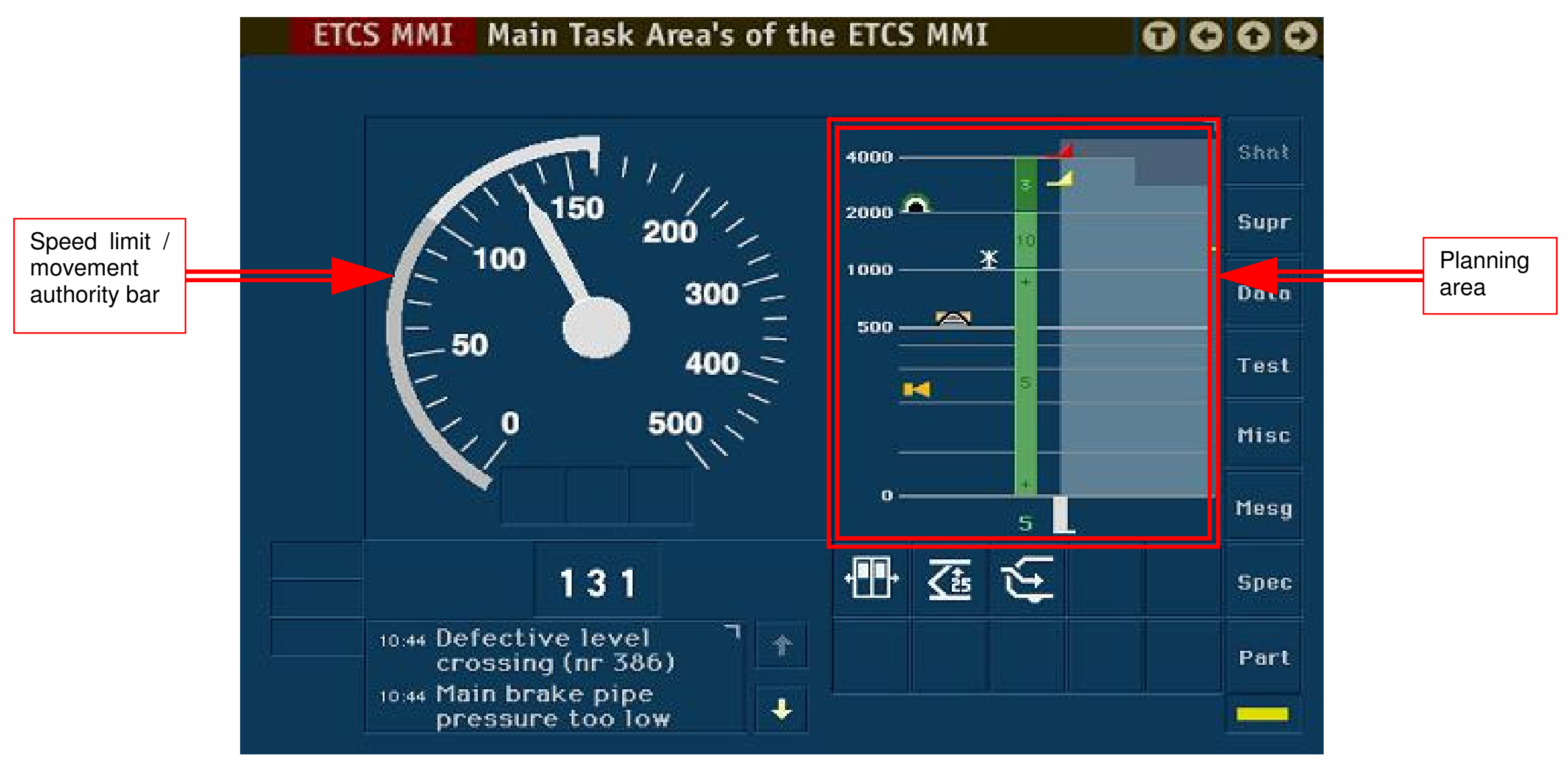

Figure 1

Sample screenshot of the ETCS DMI 
Young, M. S., Stanton, N. A. \& Walker, G. H. (2006). In loco intellegentia: human factors for the future European train driver. International Journal of Industrial and Systems Engineering, 1(4), 485-501

The signalling system is covered by ETML, and at the time of writing, it is probably fair to say that this is the least developed aspect of ERTMS. Whilst the technology is well developed, and most signalling schemes already in place, from the human factors point of view there has been relatively little progress on ERTMS signaller interfaces for the control room. Most of the effort so far has been biased towards the driver and ETCS, although there is also a clear opportunity to optimise signalling centres. Similar issues of workload and interface design abound for signallers, and the introduction of ETML technology should be used as a motivator to address these.

Finally, GSM-R is the communications network that holds it all together. This works in exactly the same way as public mobile (cellular) telephones, but on a dedicated and exclusive network for the railway. As such, it provides enhanced voice communications when compared with previous radio systems, as well as being the bearer for data transmissions in higher levels of ERTMS (see below). More technical information can be found in the EIRENE specifications $(2000 ; 2001)$, which mandate the functional and system requirements for GSM-R.

The ERTMS concept is split into three levels. Level 1 is essentially an advanced implementation of ATP, with trackside 'balises' (essentially telemetric equipment) providing the train with information about signal aspects on the road ahead. Level 2 maintains a fixed block system for signalling, but the data are now transmitted continuously via GSM-R instead of using the balises. Level 2 can either be overlaid onto existing lineside signals, or the lineside infrastructure can be removed, with the driver relying purely on the DMI for conveying speed and movement authority. Finally, Level 3 does away with fixed block signalling altogether, since the train supplies 
accurate and continuous position data to the control centre. With Level 3 in place, train separation can be maintained on a 'moving block' principle.

It could be argued that, as we step through these levels, we are imparting increasing intelligence to the technological system - and increasing capability to assume control in an emergency. How this then integrates with the existing intelligent agents in the network - the drivers and signallers - is a question of human factors.

\section{THE HUMAN FACTOR}

Possibly more than any other European country, in the UK the advent of ERTMS represents a significant change in industry culture for train operations. Whilst the UK has maintained a route-based signalling philosophy (signals convey information about the 'occupancy' of the route ahead - the driver uses signs and route knowledge to decide on the appropriate speed), continental Europe has adopted speed-signalling (signals convey information to the driver about what speed is appropriate, not the state of the route ahead) - which is more compatible with ERTMS operation. Needless to say, the impact of this change for UK drivers should not be underestimated, since their basic task and knowledge requirements (such as the dependence on route knowledge) will be fundamentally altered. Some of the key issues include mental workload, interface design, driver information needs, transitions to and from ERTMS modes, and communications. These will now be dealt with in turn. 


\section{Mental workload}

The introduction of any new technology into a system can raise concerns about mental workload (MWL). On the one hand, operating the new system could lead to overload, while the potential for increased automation can just as easily result in underload (e.g., Parasuraman, Mouloua, Molloy and Hilburn, 1996). ERTMS, with its complex information displays and capacity for automatic train protection, may well cause both problems for UK drivers if its implementation is not handled carefully. In many ways, MWL is a fundamental theme in applied research of this nature, since it can influence and be affected by a host of other design and performance factors. As such, it deserves particular attention.

Extremes of MWL can create conditions of overload or underload, which may both be detrimental to performance (Wilson and Rajan, 1995). The notion of an optimal level of MWL is based on attentional resource theory, whereby overload or underload can each cause psychological strain due to a mismatch between demands and capabilities (Byrne and Parasuraman, 1996). It is becoming accepted that optimal performance will be the reward for optimised demands (Hancock and Caird, 1993).

Overload occurs if the demands of a task are beyond the limited attentional capacity of the operator. This can be worsened if the operator becomes stressed, as stress is itself resource demanding and can compound cognitive interference (Matthews and Desmond, 1995). Conversely, those susceptible to stress or fatigue may find their performance to be worse in conditions of underload, as there is a failure to mobilise compensatory effort appropriately to cope with the demands (Desmond, Hancock and Monette, 1998). 
Underload has also been associated with passivity, with optimal MWL reflecting a need to exercise a level of control (Hockey, Briner, Tatersall and Wiethoff, 1989).

It may seem like a contradiction, but automated systems can both reduce and increase MWL. For instance, it has been observed (Hughes and Dornheim, 1995) that glass cockpits in commercial aircraft have relieved workload in areas such as reduced display clutter, and more automated flight procedures. However, the same cockpit systems have increased workload in other areas, such as increased decision options or confusion as to the operating mode (Hilburn, 1997), and increased vigilance demands (Hancock and Verwey, 1997). This can lead to mental underload during highly automated activities such as cruise flight, but mental overload during more critical operations such as take-off and landing (Parasuraman et al., 1996). Others have predicted that future systems could increase complexity or excessively reduce demands in both aircraft and cars (Labiale, 1997; Lovesey, 1995; Verwey, 1993). Both mental overload and mental underload are therefore very real possibilities, and are equally serious conditions which can lead to performance decrements, attentional lapses, and errors (Wilson and Rajan, 1995). Young and Stanton (2001) reported a study on the effects of automation on driver underload, finding that drivers were less able to resume manual control in the event of automation failure. They further implied that automated safety systems on trains might similarly increase the chances of certain types of driver error.

Under some circumstances, MWL can be both increased and decreased by the same automated system, depending on the measurement method. A study using a low-fidelity flight simulator found that the autopilot lowered subjective MWL responses, but apparently increased MWL on a secondary task measure (Thornton et al., 1992). 
Skilled pilots were used in this experiment, so the dissociation may reflect a subjective sensitivity to automation, and the effect of automaticity on the secondary task, which has been discussed previously (Liu and Wickens, 1994).

Although automation is usually implemented with the intention of reducing workload, current evidence suggests that this intention is not necessarily well-founded. Automation can be a useful assistance device in high MWL situations. But if the task MWL is already low, then automation only removes the operator from the control loop and can be detrimental to performance (Ephrath and Young, 1981). Being relieved of the task may reduce MWL, but this by no means offsets the value of being in active control (Kessel and Wickens, 1982).

Thus we see many authors are concerned about how automated controllers can lead to underload; as well as how the complexity of new systems is outpacing human information processing abilities, and inevitably results in overload (Lovesey, 1995; Wiener and Curry, 1980). Technological interventions can take any form from full operational control, to simple decision support or task assistance (Kaber and Endsley, 1997; Labiale, 1997). This is illustrated by the positions of two major aircraft manufacturers, who have ventured further into automated territory in recent years. Airbus use a 'hard protection' system in their A320 and A340 series, employing automation to prevent error, and hence it can override the pilot. Boeing, on the other hand, opted for 'soft protection' in their 777 aircraft, using automation as a tool to aid pilots, and not giving it the authority to override pilot control (Hughes and Dornheim, 1995).

Wiener and Curry (1980) believe that automation has already passed its optimal point. The assumption that automation will eliminate human error is flawed - for social 
and political reasons, humans will always be involved with the system (passengers are largely reluctant to board an aircraft without a pilot). In more than three decades of automated systems, the human element remains to provide flexibility and reliability in automated systems, to monitor the environment and take over in the event of failure (see Young, 1969, for one of the earliest benchmarks of this point). Automated systems are not error-free and, when automation errors occur, they can be more serious than manual errors due to the operator's impaired ability to cope (cf. Endsley and Kiris, 1995). At best, automation errors go unnoticed; at worst, they are compounded by human errors.

\section{$\underline{\text { Interface design }}$}

The European standard for the ETCS DMI (CENELEC, 2000) mandates a certain level of functionality to be included in every country's implementation. In addition, there are a number of optional elements that can also be included at the discretion or requirements of each member state. There is thus a clear opportunity to optimise the interface for the specific needs of the UK driving population.

Part of the mandatory specification divides the screen into six areas for providing information to the driver. One of these areas is known as the 'planning area', which provides the driver with advance warning of permitted speed limits, movement authorities and other information on the track ahead (see the right-hand portion of the screen in figure 1). Within the UK, there is a need to determine whether and how such planning information might be used to help the driver to control the train safely, reliably and productively. Where it is identified that the information would support the driver, there is a requirement to specify the nature and format for its presentation. 
Research on interface design popularly suggests that the system image should be matched to the user's mental model or internal representation of the task or device (e.g., Kantowitz and Campbell, 1996; Norman, 1988; Stanton and Young, 2000b). Keeping device behaviour consistent with the operator's expectations can therefore enhance perceptions of the system and its state. For instance, when pilots are adjusting altitude, they tend to use a constant rate of ascent (or descent) for the bulk of the change, but when they are approaching the target altitude they slow the rate to ease into the target altitude with no oscillations. Automated altitude capture, though, in some cases uses a constant rate throughout the change, levelling off almost instantly at the target altitude. This has led some pilots to believe the system was going to overshoot the intended altitude, and they have subsequently intervened (Hughes and Dornheim, 1995).

Recently, an alternative perspective has surfaced which challenges this cognitive compatibility principle. Vicente (1997) argues that the design should not centre around the user's model, as this may not be accurate (Kempton, 1986, gives a clear example of how mental models may be useful for everyday activities, even though they may be quite inaccurate). Rather, the design of the interface should be so transparent as to facilitate the development of an accurate model in the user.

In the context of UK train driving, there are essentially two types of mental model that need to be supported - one is the representation of the train dynamics, while the other is the model of the route itself. Both are crucial to effective control of the train, and both are currently highly skilled elements of drivers' expertise. In addition, the driver has considerable operational pressures to meet the timetable, resulting in a very small envelope of performance in order to maintain safe and on-time running. Whilst the enhanced (and to some extent integrated) information on the ERTMS DMI is 
probably an improvement on current displays, it does not directly help the driver optimise the many constraints placed on them (i.e., timetable, speed restrictions, signalling, stopping distance of train, etc.). At any single point in time, the drivers chosen speed could be in one of three states: too slow (failing the timetable constraint), just right (satisfying the timetable, line speed, signalling and stopping constraints), or too fast (failing the maximum line speed constraint and/or signalling and stopping constraints). Thus an 'ideal' display might seek to integrate and impart these constraints rather than just report the status of individual variables. This is the essence of Vicente's work - helping the operator to optimise the system constraints in order to produce the best outcome. Research is required to address how the additional information on the DMI will either support or disrupt this knowledge that the driver maintains. By implication, the consequences will either be to adapt the design of the interface to foster such mental models, or radically change UK driving practice to suit the system. Naturally, the optimal human factors solution would be to adapt the interface.

Indeed, there are a number of specific issues facing the industry today that could be solved with intelligent design of the DMI. Controlling train speeds on the approach to diverging junctions has always been difficult with route-based signalling, since there are few cost-effective ways of separating the speed information from the movement authority. As a consequence, signals beyond junctions are often SPAD 'hotspots'. Exploiting the planning area to provide advance information about diverging routes could help drivers to develop more effective driving strategies. Similarly, existing train protection and warning systems have been known to cause problems to drivers due to poor interface design - sometimes resulting in their being overridden inappropriately. 
The new ETCS interface provides the opportunity to integrate these systems on a single display.

\section{$\underline{\text { Information requirements }}$}

Up until the implementation of ERTMS Level 2 (without lineside signals), drivers will be faced with two different sources of information about train movements - the DMI, and the traditional external information (lineside signs and signals etc.). Most of the time, these sources should convey consistent instructions to the driver. However, there may be times when the two are in conflict. A prime example is in the most basic form of Level 1, with one balise for each lineside signal. If a driver had passed a signal showing a restrictive aspect, the ETCS would calculate a braking curve to stop at the next appropriate signal. Now, if the approach to that signal gave very clear sighting, the driver might observe the signal 'step up' from danger to a less restrictive aspect, while ETCS would not update with this new information until it had passed the relevant balise. There may be a short period, then, when the lineside signal displays 'proceed' while ETCS says 'stop'. (N.B. A more advanced version of Level 1 uses 'infill balises' between signals to help overcome this problem - although this is less than ideal from the human factors perspective, representing as it does the 'sticking plaster' approach.) Avoiding mixed messages like these is crucial to maintaining driver situation awareness (Endsley, 1995) and performance. Indeed, there are already many examples in current railway operations where disparate systems apparently contradict each other in their feedback to the driver. For instance, the Automatic Warning System (AWS) was designed to alert drivers that they are approaching a cautionary (i.e., not green) signal. 
However, this means that the driver receives a warning even when the appropriate response is to proceed (albeit more slowly). At the same time, repeater signals on the lineside, which give abbreviated information about upcoming signals, only distinguish between signals at danger (i.e., red) or otherwise - essentially the opposite criterion from AWS. Furthermore, AWS has since been extended to cover speed restrictions, so the driver also receives the same warnings in many places where there are no signals nearby. On top of all that, there are myriad other safety systems in the cab (Train Protection and Warning Systems, Driver's Reminder Appliances etc.) all working independently and sending separate streams of information to the driver. ERTMS provides a real opportunity to integrate these systems and send a single, unified stream of information.

Since many UK ERTMS routes will also be used by conventional stock for some time, the competition for the driver's attention between the lineside, the DMI, and existing train systems means that research is needed to address potential problems of confusion, distraction, and situation awareness. The relative demands of head-up versus head-down processing are probably more aligned with car driving than flying - even without lineside signals, train drivers will have to monitor the external environment for obstacles, trackside workers etc. Having said that, the lack of any lateral control demands (i.e., steering - a primary source of workload in car driving; Young and Stanton, 2002) and the extreme speeds involved (which can preclude any effective reactions to observed dangers) suggest that the visual demands of train driving lie somewhere on a continuum between automotive and aviation. So, in this somewhat unique visual environment, guidelines should be developed to optimise the design of external information sources, as well as helping drivers to cope with changing their 
dependence to the in-cab interface. Solutions such as head-up displays could also be explored. Clearly, there will be considerable overlap between this research and the previously discussed study on interface design.

\section{$\underline{\text { Transitions and migration }}$}

Fitting ERTMS to the rail network is not going to happen overnight - the economic strategy dictates that routes will be fitted in order of priority, and the significant system development involved means that this will only take place when major resignalling is required (see the final report of the ERTMS Programme Board, issued by Railway Safety and the Strategic Rail Authority in 2002, for more information on the development strategy). There will consequently be considerable periods of time when various modes of ERTMS will be fitted only to parts of the network. There are two main problems associated with this gradual implementation: one is the general migration of drivers to the new system over time, and the other involves transition between modes (including non-ERTMS, or 'Level 0') during the course of a journey. Since it is not planned to fit the entire network with ERTMS, some of these geographical transitions will be permanent. Whilst the concerns of migration and transition are related, each has its own set of issues which needs to be addressed separately.

During the early years of ERTMS implementation drivers will have to negotiate transitions between fitted and non-fitted routes. The activities that a driver must carry out at such boundaries, or monitor that the ERTMS has successfully achieved, can lead to personal peak workloads (RSSB, 2004). In addition to the system changeover, there 
will be a change in driving style to manage, particularly with Level 2 (System D) modes without line side signals.

Within ERTMS, transitions from level to level are designed to be handled by the system, although driver actions may also be required. Both system and driver actions need to be identified and addressed with regard to ergonomics research on allocation of function. The inherent risks of badly planned transitions include increased mental workload, reduced situation awareness, mode errors or mode confusions, and inappropriate levels of trust. The latter two factors are related, since a mode error could occur as the driver becomes dependent on the automatic train protection systems (cf. Parasuraman and Riley, 1997) - which could have severe consequences on a non-fitted section of route.

One of the most prevalent problems with automation, which has been particularly observed in aviation, is mode errors (Stanton and Marsden, 1996). Woods et al. (1994; pp. 6-7) define a mode error as "a device where the same action or indication means different things in different contexts (i.e., modes) and a person who loses track of the current context". The simplest example of a mode error in everyday life is attempting to set the time on a digital clock, when the clock is actually in alarm mode. System functionality and flexibility can increase with the introduction of modes (e.g., Sellen, Kurtenbach and Buxton, 1992). Complex, event-driven systems may change modes without input from, or feedback to, the operator. However, this can cause confusion and increased cognitive demand as the user tries to keep track of mode transitions and the system state (Sarter and Woods, 1995). Consequently, 'automation surprises' may occur, in which the system behaves according to specifications, yet this is quite different to that which the operator expects or desires (e.g., Palmer, 1995). Accident reports 
show that autopilot failures can lead to a loss of control and consequent crash, even though the pilot may be capable of controlling the aircraft under such conditions (Young, 1969). Failures lead to initial overcompensation and wild oscillatory responses, which may not dampen for around 20 seconds. Aircraft controls were often found hard over in the wrong direction, suggesting that the pilot either did not recognise the fault or did not react quickly enough (Young, 1969).

Excessive trust in automation has been associated with vigilance failures (Molloy and Parasuraman, 1996), and trust in automation is an issue which has attracted special attention. Muir (1994) developed a model of trust in machines, based on previous models of interpersonal trust. It was proposed that trust is based on perceptions of competence and predictability, such that it can develop over time if there is little variability in system behaviour. The level of trust in an automated system determines the human's use and monitoring of that system, and trust is governed by selfconfidence, confidence in the system, and the reliability of the system (Hancock and Parasuraman, 1992). Lee and Moray (1994) found that automation tends to be used when trust in the device exceeds operators' self-confidence in their own performance at the task. If self-confidence outweighs trust, manual control will prevail.

Under the systems perspective of ergonomics, the human and machine elements are considered as part of the same team, working together towards a common goal. It is therefore possible to draw upon knowledge of human-human cooperation to guide the design of automated systems. The types of automatic protection systems associated with ERTMS divide the driving task in a horizontal or parallel manner (cf. Stammers and Hallam, 1985). That is, the overall task of driving is shared between the human and the automation. For instance, the system gathers information about movement 
authority, calculates a braking curve to comply, and transmits this information via the DMI to the driver. The driver then follows the braking curve by making the appropriate actions on the power/brake controller. This is as opposed to vertical organisation, where the task would be divided at according to task levels (e.g., the system fully controls speed in accordance with movement authority, while the driver monitors for track obstructions etc.). Such a horizontal model of task allocation fosters teamworking and can assist in balancing task demands between team members (where those members may be human and/or non-human).

A key requirement for the safe implementation of ERTMS is that there is a process for selecting and planning transitions so that engineering considerations do not dominate fitment on any line of route to the detriment of safety and performance. Experience in the planning of Eurostar operations, and in the siting of transitions on Channel Tunnel Rail Link infrastructure concluded that a systematic approach to transition planning is vital to reduce risks. As track fitment rolls out there is a potential for unacceptable transitions to be presented to drivers. Research is necessary to explore and define the human-centred, risk-based principles for planning transitions to be applied throughout the UK track fitment stages, both at permanent and temporary transition sites to minimise these safety and performance risks.

\section{$\underline{\text { Communications }}$}

Although the previous concerns have been specifically associated with the ETCS, there are also driver risks associated with the introduction of the new telecommunications system to support ERTMS - GSM-R. Mobile phones have pervaded everyday life for 
most of the general public, and whilst their specific use as a train radio system offers greatly enhanced functionality, it could also bring increased risks. Recent research has been pointing to the conclusion that mobile phone use in cars is detrimental to performance (e.g., Haigney, Taylor and Westerman, 2000), but there is no indication so far that these results are transferable to train driving.

Young and Jenkinson (2003) reviewed the literature as part of ongoing work to provide human factors input to the UK Railway Group Standard on GSM-R radio systems. They argued that road research with lorry drivers might be more readily applicable to the rail domain. In general, though, the results from lorry trials mirror those found in car driving, and conclude that mobile phone use while driving a road vehicle is unacceptably hazardous. The main distraction effects appear to be on the low-level, tactical elements of driving, and the use of a hands-free kit does not seem to relieve the situation.

Alternatively, one might draw upon aviation operations as a parallel to rail, with the signaller playing a similar role to the air traffic controller. Communications protocols are similar in each industry (Gibson, Megaw, Young and Lowe, 2005, analysed railway communications in the context of similar research in aviation and air traffic control), and rail users could perhaps benefit from more experiential training - through which aircraft crews develop confidence in their communications technique and command of the necessary language. One of the main observable differences between communications in these domains, though, is that the party line system is employed in aviation, whilst duplex (i.e., point-to-point) calls are preferred in the rail industry (Young and Jenkinson, 2003). Again, the proven value of aircraft party line (or open 
channel) communications prompts the question of whether a similar system should be introduced for railway operations.

In addition to the potential issues of radio communication, GSM-R offers enhanced functionality for data transmissions, such as text and fax messages. This trend towards multi-modal information displays is similar to the development of digital 'datalink' technology in aviation. Whilst voice communications form an integral part of the aircraft pilot's task, increases in the volume of air traffic and pressure on turnaround times at airports have shown that voice channels can become a limiting factor in safe and efficient aircraft operations. Digital communications technology is increasingly used to provide aircraft crews with information necessary to carry out flight plans and aircraft operations, transmitting data through visual and auditory displays, and thus utilising an additional human information channel.

When Young and Jenkinson (2003) asked a group of potential users (i.e., train drivers and signallers) for their opinions as to the introduction of GSM-R, many responded in a favourable manner. The enhanced functionality, and the possibility for hand-held radios to be used outside the cab were seen as particularly positive elements. At the same time, though, most users noted the importance of equipment design and training for the successful adoption of the new system. Young and Jenkinson (2003) concluded their study with recommendations for usability, integration, and cab fitment issues associated with GSM-R.

The rail industry is somewhat unique in not legislating against radio use. However, data so far do not implicate radios as a cause of accidents. Having said that, the standard on train radio systems (RSSB, 2003) does caution about the use of radios on the move, due to concerns about visual distraction. Enhanced functionality, such as text 
or fax messaging, is tempered by certain conditions, and train operators are required to train their drivers in the risks of using radios while moving. In this respect, train radios are becoming more closely analogous to using mobile phones in cars, due to the primacy of visual input, rather than aircraft cockpit communications where visual lookout is perhaps of diminished importance. The input to the standard reflects this, drawing more heavily on the relevant literature in car- and truck-driving, where mobile phone use is a hotly debated issue (e.g., Haigney and Westerman, 2001). Additional recommendations about the consistency and integration of interface design in the cab have also been raised in the standard as points for consideration.

\section{CONCLUSIONS}

The introduction of ERTMS onto the UK rail network brings with it a plethora of human factors concerns and challenges, many of which have already been faced in the aviation and automotive industries. Indeed, the myriad overlaps between these domains provide a substantial platform on which to build railway-specific research. The train protection systems designed to ensure separation are similar in concept to Automatic Intelligent Cruise Control in cars (particularly at Level 3 ERTMS, with 'moving block' separation) or Traffic Collision and Alert Systems in aircraft. The reliance upon in-cab displays is analogous to glass cockpits, and is also emerging in cars. Signallers, communications, and the signalling system reflect their counterparts in Air Traffic Management. Finally, the overall driving task shares many visual demands as that for 
car drivers, although the reliance on head-up (i.e., external) information is perhaps not quite so crucial in a task with no steering demands.

While this paper has divided up the issues according to different applied areas of research, in actual fact the central themes of mental workload, situation awareness, and trust in automation are relevant throughout - and indeed interact with each other (cf. Stanton and Young, 2000a). Problems of transition and migration are equally applicable to GSM-R alone as they are to ERTMS in general. Moreover, the entire human-machine system is liable to fail if the technology is not handled in an integrated and holistic manner.

Fortunately, the UK rail industry is taking the issues of human factors in ERTMS very seriously, and is devoting a considerable amount of resources towards addressing them. The research areas presented in this paper are already being studied by the industry, with further projects on the signaller's interface and cab ergonomics are also planned, and the output from all of these studies is being fed directly into the development programme. This has presented an ideal opportunity for the human factors specialists involved to provide input at an early stage in the design process - which is the optimal time for making a real difference to the resulting system. Ironically, this has presented even more problems for the experimenters to cope with - such as how to develop a scenario around a system that has not yet even been defined. Nonetheless, the human factors issues discussed in this paper represent lessons learned from other transport industries with similar technologies. Despite (or perhaps because of) the rail industry following its transport counterparts with such technology, there may also be further lessons that can be transferred back out to these other domains. 
Ultimately, the design philosophy behind ERTMS reflects an example of good human factors practice when implementing advanced technology in any system. There is very little attempt to replace the driver or take over any driving tasks (with the exception of the redundant safety systems); ERTMS rather supports and enhances the activities that the driver already undertakes. Such an approach helps to avoid many of the problems of automation discussed in this paper, thus keeping the driver in the control loop (cf. Endsley and Kiris, 1995). The devil truly lies in the detail, though, and we should not become complacent in maintaining the human factors effort across these research streams. An intelligent in-cab system is all very well, but if it is not implemented appropriately, train drivers might just end up as computer operators. In that case, as has been observed in aviation, they may best advised to switch it off and look out of the window.

\section{ACKNOWLEDGEMENTS}

Thanks to Mike Nendick of the Civil Aviation Safety Authority in Australia and to two anonymous reviewers for their helpful comments on earlier drafts of this paper. 


\section{REFERENCES}

Byrne, E. A., and Parasuraman, R. (1996). Psychophysiology and adaptive automation. Biological Psychology, 42, 249-268.

CENELEC (Comité Européen de Normalisation Electrotechnique, 2000). European Standard - Railways Applications: European Rail Traffic Management System Driver Machine Interface. Document no. WGA9D prEN 50XX6.

Desmond, P. A., Hancock, P. A., and Monette, J. L. (1998). Fatigue and automationinduced impairments in simulated driving performance. Transportation Research Record, 1628, 8-14.

EIRENE (European Integrated Railway Radio Enhanced Network, 2000). Functional Requirements Specification Issue 5.0. Document no. MDA029D009.

EIRENE (European Integrated Railway Radio Enhanced Network, 2001). System

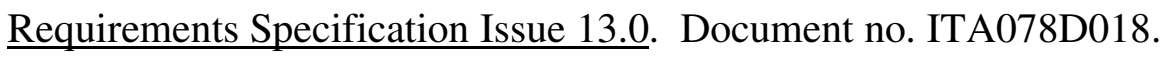

Endsley, M. R. (1995). Toward a theory of situation awareness in dynamic systems. Human Factors, 37(1), 32-64.

Endsley, M. R., and Kiris, E. O. (1995). The out-of-the-loop performance problem and level of control in automation. Human Factors, 37(2), 381-394. 
Ephrath, A. R. and Young, L. R. (1981). Monitoring vs. man-in-the-loop detection of aircraft control failures. In J. Rasmussen and W. B. Rouse (Eds.), Human detection and diagnosis of system failures (pp. 143-154). New York: Plenum.

ERTMS Programme Board (2002). ERTMS: Towards a Better, Safer Rail System. London: Railway Safety and the Strategic Rail Authority.

Gibson, W. H., Megaw, E. D., Young, M. S. and Lowe, E. (2005). A taxonomy of human communication errors and application to railway track maintenance. Manuscript in press ( $\underline{\text { Cognition, Technology and Work }})$.

Haigney, D. E., Taylor, R. G. and Westerman, S. J. (2000). Concurrent mobile (cellular) phone use and driving performance: task demand characteristics and compensatory processes. Transportation Research Part F: Traffic Psychology and Behaviour 3(3), 113-121.

Haigney, D. and Westerman, S. J. (2001). Mobile (cellular) phone use and driving: a critical review of research methodology. Ergonomics, 44(2), 132-143.

Hancock, P. A., and Caird, J. K. (1993). Experimental evaluation of a model of mental workload. Human Factors, 35, 413-429. 
Hancock, P. A., and Parasuraman, R. (1992). Human factors and safety in the design of Intelligent Vehicle-Highway Systems (IVHS). Journal of Safety Research, 23(4), 181-198.

Hancock, P. A., and Verwey, W. B. (1997). Fatigue, workload and adaptive driver systems. Accident Analysis and Prevention, 29(4), 495-506.

Hilburn, B. (1997). Dynamic decision aiding: the impact of adaptive automation on mental workload. In D. Harris (Ed.), Engineering psychology and cognitive ergonomics. (pp. 193-200). Aldershot: Ashgate.

Hockey, G. R. J., Briner, R. B., Tatersall, A. J., and Wiethoff, M. (1989). Assessing the impact of computer workload on operator stress: the role of system controllability. Ergonomics, 32(11), 1401-1418.

Hughes, D., and Dornheim, M. A. (1995, January 30). Accidents direct focus on cockpit automation. Aviation Week and Space Technology, 52-54.

Human Engineering Limited (2003). Early human factors analysis for UK-ERTMS driving (intermediate version). Report no. HEL/RS/02768a/RT14 for Rail Safety and Standards Board, 29 August 2003. 
Kaber, D. B., and Endsley, M. R. (1997). Out-of-the-loop performance problems and the use of intermediate levels of automation for improved control system functioning and safety. Process Safety Progress, 16(3), 126-131.

Kantowitz, B. H., and Campbell, J. L. (1996). Pilot workload and flightdeck automation. In R. Parasuraman and M. Mouloua (Eds.), Automation and human performance: Theory and applications. (pp. 117-136). Mahwah, NJ: Lawrence Erlbaum Associates.

Kempton, W. (1986). Two theories of home heat control. Cognitive Science, 10, 75-90.

Kessel, C. J., and Wickens, C. D. (1982). The transfer of failure-detection skills between monitoring and controlling dynamic systems. Human Factors, 24(1), 49-60.

Labiale, G. (1997). Cognitive ergonomics and intelligent systems in the automobile. In Y. I. Noy (Ed.), Ergonomics and safety of intelligent driver interfaces. (pp. 169-184). Mahwah, NJ: Lawrence Erlbaum Associates.

Lee, J. D., and Moray, N. (1994). Trust, self-confidence, and operators' adaptation to automation. International Journal of Human-Computer Studies, 40, 153-184.

Liu, Y., and Wickens, C. D. (1994). Mental workload and cognitive task automaticity: an evaluation of subjective and time estimation metrics. Ergonomics, 37(11), 18431854. 
Lovesey, E. (1995). Information flow between cockpit and aircrew. Ergonomics, 38(3), 558-564.

Matthews, G., and Desmond, P. A. (1995). Stress as a factor in the design of in-car driving enhancement systems. Le Travail Humain, 58(2), 109-129.

Muir, B. M. (1994). Trust in automation: Part I. Theoretical issues in the study of trust and human intervention in automated systems. Ergonomics, 37(11), 1905-1922.

Molloy, R., and Parasuraman, R. (1996). Monitoring an automated system for a single failure: Vigilance and task complexity effects. Human Factors, 38(2), 311-322.

Norman, D. A. (1988). The psychology of everyday things. New York: Basic Books.

Palmer, E. (1995). 'Oops, it didn't arm.' - A case study of two automation surprises. $\underline{\text { th }}$ International Symposium on Aviation Psychology. Columbus, Ohio: Ohio State University.

Parasuraman, R., Mouloua, M., Molloy, R., and Hilburn, B. (1996). Monitoring of automated systems. In R. Parasuraman and M. Mouloua (Eds.), Automation and human performance: Theory and applications. (pp. 91-115). Mahwah, NJ: Lawrence Erlbaum Associates. 
Parasuraman, R., and Riley, V. (1997). Humans and automation: use, misuse, disuse, abuse. Human Factors, 39(2), 230-253.

RSSB (2003). GE/RT8080: Train Radio Systems for Voice and Related Messaging Communications (Issue One). London: Rail Safety and Standards Board.

RSSB (2004). Impact of the European Rail Traffic Management System (ERTMS) on driver workload. London: Rail Safety and Standards Board.

RSSB (2005). The Railway Strategic Safety Plan 2005. London: Rail Safety and Standards Board.

Sarter, N. B., and Woods, D. D. (1995). How in the world did we ever get into that mode? Mode error and awareness in supervisory control. Human Factors, 37(1), 519.

Sellen, A., Kurtenbach, G. and Buxton, W. (1992). The prevention of mode errors through sensory feedback. Human Computer Interaction, 7(2), 141-164.

Stammers, R. B. and Hallam, J. (1985). Task allocation and the balancing of load in the multi-man-machine system - some case studies. Applied Ergonomics, 16 (4), 251257. 
Stanton, N. A., and Marsden, P. (1996). From fly-by-wire to drive-by-wire: safety implications of automation in vehicles. Safety Science, 24(1), 35-49.

Stanton, N. A. and Young, M. S. (2000a). A proposed psychological model of driving automation. Theoretical Issues in Ergonomics Science, 1(4), 315-331.

Stanton, N. A., and Young, M. S. (2000b). The role of mental models in using Adaptive Cruise Control. Proceedings of the International Ergonomics Association $14^{\text {th }}$ Triennial Congress and the HFES $44^{\text {th }}$ Annual Meeting, San Diego, CA., July 30August 4 2000. Santa Monica, CA: HFES.

Stanton, N. A., and Young, M. S. (2005). Automatic Intelligent Cruise Control. Journal of Intelligent Systems (manuscript submitted for publication)

Thornton, C., Braun, C., Bowers, C., and Morgan, B. B. (1992). Automation effects in the cockpit: A low-fidelity investigation. Proceedings of the Human Factors Society 36th Annual Meeting: Vol. 1 (pp. 30-34).

Verwey, W. B. (1993). How can we prevent overload of the driver? In A. M. Parkes and S. Franzen (Eds.), Driving future vehicles. (pp. 235-244). London: Taylor and Francis.

Vicente, K. J. (1997). Interface design: Is it always a good idea to design an interface to match the operator's mental model? Ergonomics Australia On-Line, 11(2). 
Walker, G. H., Stanton, N. A., and Young, M. S. (2001). Where is computing driving cars? International Journal of Human Computer Interaction, 13(2), 203-229.

Walker, G. H., Stanton, N. A., Gibson, H., Baber, C., Young, M. S., and Green, D. (2005). Analysing the role of communications technology in C4i scenarios: A distributed cognition approach. Journal of Intelligent Systems (manuscript submitted for publication).

Wiener, E. L., and Curry, R. E. (1980). Flight-deck automation: promises and problems. Ergonomics, 23(10), 995-1011.

Wilson, J. R., and Rajan, J. A. (1995). Human-machine interfaces for systems control. In J. R. Wilson and E. N. Corlett (Eds.), Evaluation of human work: a practical ergonomics methodology. (pp. 357-405). London: Taylor and Francis.

Woods, D. D., Johannesen, L. J., Cook, R. I., and Sarter, N. B. (1994). Behind human error: cognitive systems, computers, and hindsight. State of the art report. Ohio: CSERIAC.

Young, L. R. (1969). On adaptive manual control. Ergonomics, 12(4), 635-675.

Young, M. and Jenkinson, J. (2003, October). Human factors issues raised by the proposed introduction of GSM radio telecommunications into the UK rail 
environment. Paper presented at the First European Conference on Rail Human Factors, York, UK.

Young, M. S. and Stanton, N. A. (2001). Out of control. New Scientist, 2315 (3 Nov 2001), 44-47.

Young, M. S. and Stanton, N. A. (2002). Malleable Attentional Resources Theory: A new explanation for the effects of mental underload on performance. Human Factors, 44(3), 365-375.

Young, M. S. and Stanton, N. A. (2004). Taking the load off: investigations of how adaptive cruise control affects mental workload. Ergonomics, 47(9), 1014-1035. 